Indian J. Anim. Hlth. (2020), 59(1) : 33-38

DOI:10.36062/ijah.59.1.2020.33-38

\title{
ANTIMICROBIAL RESISTANCE: A GLOBAL MENACE: ONE HEALTH APPROACH ${ }^{\dagger}$
}

\author{
S. BHOWMICK ${ }^{1}$, J. SUNDER ${ }^{1}$, S. N. JOARDAR ${ }^{2}$ AND I. SAMANTA*2 \\ ${ }^{1}$ ICAR-Central Island Agricultural Research Institute, Animal Science Department, Port Blair-744 \\ 105, Andaman \& Nicobar Islands, India \\ ${ }^{2}$ Department of Veterinary Microbiology, West Bengal University of Animal and Fishery Sciences, \\ Kolkata-700 037, West Bengal, India

\begin{abstract}
Human civilization is at risk of zoonotic infection via direct contact due to close proximity with livestock/poultry/fish, environmental contamination, and intake of contaminated food items which causes enormous economic losses due to loss of man-days and associated production level. The situation becomes more complicated due to transmission of antimicrobial resistant bacteria into human food chain from livestock or fishes. It creates mortality and extra financial burden associated with increased treatment cost and prolonged hospital stay. Recent estimate indicates about possibility of 10 million deaths every year due to infection with antimicrobial resistant organisms to be occurred by 2050 which is even more than projected death by cancer. This is a multifactorial and complex issue which is associated with several core sectors such as human and animal health, fishery, agriculture, environment etc. We have wasted a sufficient time in 'blame game' to each other. Time has come to work together under same umbrella with a true 'One medicine: One world: One health' approach. Considerable efforts and initiatives are taken by different Universities / Institutes / Private Companies to address the issue to sustain normal production and productivity of animals, poultry and fishes.
\end{abstract}

Key words: Antimicrobial resistance, Food animals, One health, Veterinary

Human civilization is at risk of zoonotic infection via direct contact due to close proximity with livestock/poultry/fish, environmental contamination, and intake of contaminated food items which causes enormous economic losses due to loss of man-days and associated production level. The situation becomes more complicated due to transmission of antimicrobial resistant bacteria into human food chain from livestock or fishes. It creates mortality and extra financial burden associated with increased treatment cost and prolonged hospital stay. Every year 700,000 people lose their life battling to antimicrobial resistance (AMR) and 10 million deaths throughout the world is projected from it by 2050 which is even more than projected death by cancer (Taneja and Sharma, 2019). Bacterial resistance to antibiotics is an immediate threat to human, livestock, fish and environment all over the world. This problem has tormented clinicians and policy makers but it seems there is no straightforward way to outwit this problem. The issue of AMR has become so crucial that United Nations held a special meeting in 2016 to monologue only this issue (Holpunch, 2016). In that meeting, the issue was said to be of as much significance as climate change and it was considered to require a global response (Holpunch, 2016).

This is a multifactorial and complex issue which is associated with several core sectors such as

\footnotetext{
This paper was presented at the National Seminar on Antimicrobial resistance - A global menace: One health approach on March 07, 2020 at West Bengal University of Animal and Fishery Sciences, Kolkata, India organised by Indian Journal of Animal Health

*Corresponding Author
} 
human and animal health, fishery, agriculture, environment etc. We have wasted a sufficient time in 'blame game' to each other. Time has come to work together under same umbrella with a true 'One medicine: One world: One health' approach. Considerable efforts and initiatives are taken by different Universities / Institutes / Private Companies to address the issue to sustain normal production and productivity of animals, poultry and fishes.

\section{AMR: Global peril}

Increase in antibiotic resistant poses a remarkable threat to development, food security and health. Economic prognosis estimates that AMR would reduce gross domestic product (GDP) by $2-3.5 \%$ with a drop in livestock by 3-8\%, costing USD 100 trillion to the world by 2050 (O'Neill, 2014). In 2019 AR Threats Report, it was reported that more than 2.8 million antibiotic-resistant infections occur in the U.S. each year, and more than 35,000 people die as a result i.e. is roughly one death from ABR every 15 minutes and one infection every 11 seconds (CDC, 2019). By trainings, technical support and workshops, WHO supported 57 low and middle income countries to monitor AMR. Since the AMR, was prioritized by World Health Organization (WHO), several world chief from Europe and other parts of the world has framed their action plans for the regulation of AMR (Smith et al., 2016). It will be a big provocation to address the problem for the health care providers and policy makers. Consumption of antimicrobial in production of food animal, globally, is expected to increase as high as $67 \%$ by 2030 by BRICS countries (Brazil, Russia, India, China and South Africa) thus shifting to intensive farming system in large scale where subtherapeutic doses of antibiotics are used routinely (Brower et al., 2017). WHO established Global Antibiotic Resistance Partnership (GARP) to develop short and long term policy recommendations in low and middle income countries (India, Kenya, South Africa and Vietnam) where the MDR is severe. Considering AMR as a global threat, UN General Assembly in New York considered AMR as the fourth health related issue in September 2016 preceded by HIV, non-communicable diseases and Ebola (ICAR News, 2019).

\section{AMR: Indian peril}

India carries one of the largest loads of drug resistant pathogens worldwide as it is one of the world's largest consumers of antimicrobial drugs. By 2050, two million deaths are estimated to occur in India due to AMR (Gelband et al., 2015). The current mortality rate of infectious disease in India is $416.75 / 100,000$ persons (Laxminarayan et al., 2013) which is double the rate present in United States where it is $200 / 100,000$ persons (Armstrong et al., 1999). Unbridled use of antimicrobial agents in livestock, hospitals, aquaculture farms and poultry, aimless disposal of waste and wastewater from animal farms, municipalities and pharmaceutical industries into lakes, rivers and other water bodies over the years, have contributed to the development of colossal issue of antibiotic resistance (Shivagami et al., 2020). In the recent times, the quantity of diet obtained from wheat and rice gradually decreased and the intake of animal protein grew from seven to twenty-five grams per capita in five decades (CDDEP, 2017). Because of the increasing demand, there is an increasing trend to establish commercial livestock and poultry farms, and aquaculture establishments in developing countries.

\section{Research on AMR in India}

Out of 2152 studies, $48.3 \%$, studies were done on humans while $4.2 \%$ studies done on environment, $3.3 \%$ studies on animals, $0.5 \%$ studies on 'One Health' and the rest were miscellaneous (Gandra et al., 2017).

In commercial livestock, poultry farms and in aquaculture, the antibiotics are used mainly for three reasons, i.e. therapeutic, metaphylaxis and as antibiotic growth promoters. Because of the partial metabolism of antimicrobials, most of the antibiotic dose (30-80\%) given to animals that are used for food are excreted into the environment. Also the antibiotics which are included in animal feeds will reach the soil sediments directly. Another origin of antimicrobial contamination in environment is through use of waste generated by animal farms which are used as manure to fertilize 
the soil (Ramesh, 2016). Most of the antibiotics are deposited in aquatic systems such as rivers and lakes. If the soil is loaded with these antibiotics it becomes the best source for spreading antibiotic resistant bacteria through agricultural practices. For example, Pseudomonas and Acinetobacter which are opportunistic pathogens residing in soil, can acquire antibiotic resistance genes from the soil and become resistant bacteria (Argudin et al., 2017). Antibiotics are also used in aquaculture sector for prophylactic and therapeutic purposes. There is a common practice where the organic waste from poultry and livestock which are sometimes rich in resistant bacteria are fed to farm fish under the integrated farming system. It is in fact $70-80 \%$ antibiotics end up in the environment which are used in the aquatic farming (Washer and Joffe, 2006).

Some studies on AMR in India are as follows: AMR research in humans: Resistance rate among bacteria that cause infections in India is high. Rajivgandhi et al. (2018) identified TEM, SHV, OXA and CTX-M genes in ciprofloxacin resistant uropathogen strains. Out of 300 blood samples collected from clinically diagnosed neonatal septicemia from tertiary care center, South India, $97.43 \%$ of K. pneumoniae and $2.56 \%$ of $K$. oxytoca were ESBL producers (Anitha and Anuradha, 2019). Mehdi and Neema (2018) estimated the prevalence of beta-lactamase production among Enteriobacteriaceae on routine basis using simple phenotypic methods. They found $38.11 \%$ of isolates were ESBL producers followed by $3.20 \%$ isolates were MBL producers and $0.56 \%$ were AmpC producers out of 530 Enteriobacteriaceae. Out of $180 P$. aeruginosa isolates, $23.88 \%$ isolates were isolated from pus and $18.88 \%$ isolates were isolated from urine. In these samples, $59.01 \%$ isolates were MBL producers, $27.71 \%$ isolates were ESBL producers and $21.66 \%$ isolates were Amp C producers. And $14.11 \%$ isolates showed coproduction of ESBL/AmpC/MBL production, $18.89 \%$ isolates were MDR, $1.66 \%$ were XDR (Choudhary et al., 2018).

AMR research in food animals: The same antibiotics which are used commonly in humans are sometimes used in food animals, raising the concern of effectiveness of these antibiotics in human health. Meta-analysis report of animals on India suggested that the pooled prevalence of ESBL were $26,11,6$ and $8 \%$ on north, east, south and central zones, respectively and $12,5,8,8,12,13$ and 33\% for the years 2013, 2014, 2015, 2016, 2017, 2018,2019 , respectively and the species wise stratified results showed a predominance of $11 \%$ ESBL producing $K$. pneumoniae strains compared to E.coli (7\%) and Pseudomonas spp. (5\%) (Kuralayanapalya et al., 2019). Mahanti et al. (2018) detected the presence of CTX-M producing Klebsiells spp. in healthy broiler, indigenous and kuroiler birds reared in West Bengal during November 2014-February 2015. Out of 321 cloacal swabs, $10.7 \%$ of Klebsiella spp. isolates were CTX$\mathrm{M}$ producers whereas $51.5 \%$ possessed blaSHV and $48.5 \%$ possessed blaTEM with blaCTX-M genes, respectively which could be transmitted to the human food chain directly or indirectly. Out of 219 faecal samples collected from piglets with diarrheoa, pig farmers and water sources in NorthEast India, $66.98 \%, 70.91 \%$, and $56.25 \%$ were ESBL producers and $9.68 \%, 1.21 \%, 2.02 \%$ were recorded as Shiga toxin E.coli (STEC). 59.38\% of STEC isolates harboured ESBL/beta-lactamase genes with $32.81 \%$ STEC isolates being positive for multiple ESBL/beta-lactamase genes (Puii et al., 2019). Out of 450 composite milk samples collected from all agro-climatic zones of West Bengal, $9.6 \%$ of $S$. aureus detected were methicillin resistant $S$. aureus (MRSA) whereas $12.8 \%$ and $4.3 \%$ isolates possessed staphylococcal enterotoxins sei and seg, respectively (Mahanti et al., 2020).

AMR research in fishery: Situation of aquaculture is different from that of livestock. Out of total 131 bacteria isolated, resistance pattern of streptomycin, cephalexin, rifampicin and nitrofurantoin were found to be more than $60 \%$ both by marine and freshwater bacterial isolates (Sunder et al., 2006). Saharan et al. (2019) obtained 160 faecal fish samples from Rajasthan, out of which 95\% of E.coli and and Salmonella spp. Isolates were resistant against streptomycin while 
for $S$. aureus it was observed against trimethoprim. Singh et al. (2017) collected fresh seafood from retail market from Western Mumbai between August 2013 and April 2014. They observed that $90 \%$ of the isolates were resistant to $3^{\text {rd }}$ generation cephalosporins and $65 \%$ of the isolate were resistant to aztreonam, $40.82 \%$ resistant to ertapenem and $31.36 \%$ were resistant to meropenem. Within theses $38.46 \%$ isolates were MDR and $76.92 \%, 63.3 \%$ and $44.37 \%$ of the isolates were detected with blaCTX, blaSHV and blsTEM genes. Moreover, blaNDM was detected in two of the ESBL isolates.

AMR research in environment: Use of animal manure in agriculture is one of the common practices in India. Waste of animal is one of the main links in spreading AMR as they generally containing ARB. Water sources laden with ARB and ARGs are being reported from various parts of India. Pharmaceuticals waste water and hospital effluents are also released into water bodies without any treatment contaminating the environment. Out of 18 agricultural sampling points in Kalyani, West Bengal 158 multidrug resistant bacteria were isolated and $90 \%$ of them were resistant against cefotaxime and $68.75 \%$ of isolates harbored at least 2 ESBL genes and $31.25 \%$ either have blaSHV or blaTEM gene (Sen and Sarkar, 2018). The rate of ESBL producers was $17.4 \%$ among gram negative bacteria isolated from north Indian rivers with detection of resistance genes like bla $a_{N D M}$ and bla $_{\text {оХA }}$ (Azam et al., 2016).

Lacunae on AMR control: Due to the poor management of waste which contains antibiotics, ABR bacteria, ARGs from pharmaceutical factories, farms, healthcare settings, it has led to the emergence and spread of AMR. Limited awareness among public and government commitment, over the counter sale of antibiotics, endemic infections, malnutrition, poor sanitation, weak surveillance and regulatory system, availability of inexpensive antibiotics, and poor income are creating the perfect conditions for a large-scale selection and dissemination of ABGs in India. Evaluation of nationwide comparison of
AMR rise and fall in India is also prevented by lack of adequate research. While many research have been done to study the resistance profiles of bacteria isolated from poultry, livestock and aquaculture, mechanism of AMR, resistant bacteria biology, expanding the existing antimicrobials chemical diversity and using nonantibiotic agents as substitutes, the reason for antibiotic use during animal rearing and rate of antibiotic used are poorly represented in published literature. There is not much research into the rapid antimicrobial susceptibility diagnostics, qualitative studies on farmer's knowledge and the antibiotic they use in their operations.

\section{Conclusion}

The One health approach spotlights the interrelatedness among animal health, human health, environment and food and fosters synergistic efforts on the part of health officials dealing with these spheres (Dahal et al., 2017). This condition is worsen by the fact that the environmental contribution for AMR resistance differs geographically all over the world and hence conditions established by one developed nation may not be applicable in developing nations like India. India has recently launched National Action Plan (NAP) on AMR in April 2017 along with 'Delhi declaration on Antimicrobial Resistance' supported by 12 stakeholder ministries with the key strategy to promote investment for research to mitigate the issue (Government of India, 2017).

In March 2018, a set of draft standards for antibiotic discharge in pharmaceutical industry effluents was prepared by Central Pollution Control Board (CPCB). Government of India has also launched a 'National Programme on Containment of Antimicrobial Resistance' during the $12^{\text {th }}$ Five Year Plan (2012-2017) under which 10 medical colleges and labs were included initially and afterwards extended to 20 state medical colleges from 18 states (as of October 2018) to tackle this issue. FAO in alliance with Indian Council of Agricultural Research (ICAR) organized a meeting at Kolkata, India on $7-8^{\text {th }}$ March 2017 and facilitated establishment of Indian 
Network for Fishery and Animals Antimicrobial Resistance (INFAAR) with sole objective to generate nationwide, structured, quality data through surveillance and research on AMR specific to livestock and fisheries sectors for strengthening knowledge and better understanding of AMR. In India, the Ministry of Agriculture's early implementation of programs such as Assistance to the States for Control of Animal Diseases (ASCAD), the National Animal Disease Reporting System (NADRS), and the National Livestock censuses, indicates that the

\section{REFERENCES}

Anitha TK and Anuradha K, 2019. Neonatal sepsis due to ESBL producing Klebsiella. Indian $\mathbf{J}$ Microbiol Res, 6(2): 113-116

Argudin MA, Deplano A, Meghraui A, Dodemont M, Heinrichs A et al., 2017 . Bacteria from animals as a pool of antimicrobial resistance genes. Antibiotics (Basel), 6(2): E12, doi: 10.3390/ antibiotics6020012

Armstrong GL, Conn LA and Pinner RW, 1999. Trends in infectious disease mortality in the US during the $20^{\text {th }}$ century. Jama, 281(1): 61-66, PMID: 9892452

Azam M, Jan AT and Haq QM, 2016. Bla CTX-M-152, a novel variant of CTX-M-group-25, identified in a study performed on the prevalence of multidrug resistance among natural inhabitants of river Yamuna. India Front Microbiol, 7: 176

Brower CH, Mandal S, Hayer S, Sran M, Zehra A et al., 2017. The prevalence of extended-spectrum beta-lactamase-producing multidrugresistant Escherichia coli in poultry chickens and variation according to farming practices in Punjab, India. Environ Health Perspect, 125(7): 077015, doi: 10.1289/EHP292

The Centre for Disease Dynamics, Economics and Policy (CDDEP), 2017. Antibiotic Use and Resistance in Food Animals: Current Policy and Recommendations. Available from: https:// www.eddep.org/publications/antibiotic_ use and_resistance_food_animals_current_ policy_and_recommendations/

Center for Disease Control (CDC), 2019. Antibiotic Resistance Threats in the United States (2019 AR Threats Report). Available from:https:// www.cdc.gov/drugresistance/pdf/threats-report/ capacity for widespread data collection is in place, and more extensive data collection on antibiotic use in farming may be possible in the coming years (CDDEP, 2016). However, many of the planned activities on AMR surveillance have yet not been completed due to lack of cooperation between central and state governments. "What India needs is a clear roadmap for two things- one to phase out use in animals of antibiotics which are critically important for humans, and two, to stop antibiotic misuse for mass disease prevention", says Khurana (CSE assessment, 2018).

2019-ar-threats-report-508.pdf, accessed on April 3, 2020

Center for Disease Dynamics, Economics \& Policy (CDDEP), Wahington DC, New Delhi, 2016. Antibiotic Use and Resistance in Food Animals, Current Policy and Recommendations.

Choudhary V, Pal N and Hooja S, 2018. Phenotypic detection of ESBL, AmpC, MBL beta-lactamases among clinical isolates of P.aeruginosa in tertiary care hospital of north India. Int J Curr Med Pharm Res, 4(12): 3902-3906

Center for Science and Environment (CSE), 2018. An assessment on India's National Action Plan on AMR (2017-2021), available from: https:// www.cseindia.org/world-antibiotic-awarenessweek-9145, accessed on April 4, 2020

Dahal R, Upadhyay A and Ewald B, 2017. One health in South Asia and its challenges in implementation from stakeholder perspective. Vet Res, 181: 626

Gandra S, Joshi J, Trett A, Lamkang AS and Laxminarayan R, 2017. Scoping report on antimicrobial resistance in India. Washington, DC: Center for Disease Dynamics, Economics \& Policy

Gelband H, Miller-Petrie M, Pant S, Gandra S, Levinson J et al., 2015. The state of the world's antibiotics. Washington DC: Center for Disease Dynamics. Economics \& Policy, available in https://cddep.org/publications/state_worlds_ antibiotics_2015/

Government of India, 2017. National Action Plan on Antimicrobial Resistance (NAP-AMR) 20172021, available from: http://www.searo.who.int/ 
india/topics/antimicrobial_resistance/ nap_amr.pdf, accessed on April 1, 2020

Holpunch A, 2016. UN meeting tackles the 'fundamental threat' of antibiotic resistant superbugs, UK: The Guardian

ICAR News,2019. A Science and Technology Newsletter: ICAR initiatives on AMR, 25(3): 28, available from: https://icar.org.in/sites/default/files/ICAR\% 20News\%20July-September\%202019_Low\% 20Res.pdf, accessed on April 4, 2020

Kuralayanapalya SP, Patil SS, Hamsapriya S, Shinduja $\mathrm{R}$, Roy $\mathrm{P}$ et al., 2019. Prevalence of ESBL producing bacteria from animal origin: A systematic review and meta-analysis report from India. PLoS ONE, 14(9): e0221771

Laxminarayan R, Duse A, Wattal C, Zaidi AK, Wertheim HF et al., 2013. Antibiotic resistancethe need for global solutions. Lancet Infect Dis, 13(12): 1057-1098

Mahanti A, Ghosh P, Samanta I, Joardar SN, Bandyopadhyay S et al., 2018. Prevalence of CTX-M-producing Klebsiella spp. in broiler, kuroiler, and indigenous poultry in West Bengal state. Microb Drug Resist, 24(3): 299-306

Mahanti A, Joardar SN, Bandyopadhyay S, Banerjee J, Ghosh S et al., 2020. Characterization of methicillin-resistant and enterotoxins producing Staphylococcus aureus in bovine milk in India. J Agric Food Res, 2: 100017

Mehdi K and Neema S, 2018. Phenotypic detection betalactamase production among Enteriobacteriaceae isolates by novel disc placement method. Br J Biomed Res, 2(2): 303-309

O’Neill J, 2014. Antimicrobial Resistance: Tackling a crisis for the health and wealth of nations. Review on Antimicrobial resistance, tackling drug resistant infections globally, available from: https://amrreview.org/sites/default/files/ A M R \% $20 \mathrm{Review} \% 20 \mathrm{Paper} \% 20$ $\% 20$ Tackling\%20a\%20crisis\%20for \%20the $\% 20$ health $\% 20$ and $\% 20$ wealth $\% 20$ of $\% 20$ nat ions_1.pdf, accessed on April 1, 2020

Puii L, Dutta TK, Roychoudhury P, Kylla H, Chakraborty S et al., 2019. Extended spectrum beta-lactamase producing Shiga-toxin producing
- Escherichia coli in piglets, humans and water sources in North East region of India. Lett Appl Microbiol, 69: 373-378

Rajivgandhi G, Maruthupandy M, Ramachandran G, Priyanga M and Manoharan N, 2018. Detection of ESBL genes from ciprofloxacin resistant gram negative bacteria isolated from UITs. Front Lab Med, 2(1): 5-13

Ramesh S, 2016. Antibiotic usage patterns in animal husbandry and food safety: regulations and practice CIBA report

Saharan VV, Verma P and Singh AP, 2019. High prevalence of antimicrobial resistance in E. coli, Salmonella spp. and S. aureus isolated from fish samples in India. Aquacul Res, 51(3): 1200-1210

Sen S and Sarkar K, 2018. Screening of ESBL producing bacterial isolates of agricultural soil and profiling for MDR. Ann Agrar Sci, 16(3): 272-280

Shivagami K, Vignesh VJ, Srinivasan R, Divyapriya G and Nambi IM, 2020. Antibiotic usage, residues and resistance genes from food animals to human and environment: An Indian scenario. J Environ Chem Eng, 8(1): 102221

Singh AS, Lekshmi M, Prakasan S, Nayak BB and Kumar S, 2017. Multiple antibiotic resistant, ESBL-producing Enteriobacteriaceae in fresh Seafood. Microorganisms, 5(3): 53

Smith E, Lichten CA, Taylor J, MacLure C, Lepetit L et al., 2016. Evaluation of the EC action plan against the rising threats from antimicrobial resistance. Final Report. European Commission. Available from: https://www.ec.europa.eu/ health/amr/sites/amr/files/amr_finalreport_2016_rand.pdf, accessed on March 31, 2020

Sunder J, Jeyakumar S, Ahlawat SPS, Rai RB, Kundu A et al., 2006. Antibiotic resistance pattern of bacterial isolates from fishes of Andaman and Nicobar Islands. Indian J Fish, 53(2): 231-235

Taneja N and Sharma M, 2019. Antimicrobial resistance in the environment-The Indian scenario, Indian J Med Res, 149(2): 119-128

Washer P and Joffe H, 2006. The hospital superbug social representations of MRSA. Social Sci Med, 63(8): 2141-2152

Received-07.03.2020, Accepted-13.05.2020, Published-01.06.2020

[The article was presented in the National Seminar on Antimicrobial resistance - A global menace: One health approach on March 07, 2020 at West Bengal University of Animal \& Fishery Sciences, Kolkata, West Bengal organised by Indian Journal of Animal Health ] 